\title{
Structural and electrical properties of bismuth magnesium tantalate pyrochlores.
}

\begin{abstract}
The subsolidus cubic pyrochlore phases in the $\mathrm{Bi} 2 \mathrm{O} 3-\mathrm{MgO}-\mathrm{Ta} 2 \mathrm{O} 5$ (BMT) system were prepared with the proposed formula, $\mathrm{Bi} 3+(5 / 2) \mathrm{xMg} 2-\mathrm{xTa} 3-(3 / 2) \mathrm{xO} 14-\mathrm{x}(0.12 \leq \mathrm{x} \leq 0.22)$. Replacement of smaller cations, $\mathrm{Mg} 2+$ and $\mathrm{Ta} 5+$ by larger $\mathrm{Bi} 3+$ cations with considerable oxygen non-stoichiometry within structure was proposed. The synthesised samples were confirmed phase pure by X-ray powder diffraction and their refined lattice parameters were in the range of 10.5532(4)-10.5672(9) $\AA$. The grain sizes of the samples determined by SEM analysis were in the range of $0.6-10.60 \mu \mathrm{m}$ and their average relative densities were more than $80 \%$. Five infrared-active modes were also observed in their FTIR spectra due to their metalsingle bondoxygen bonds. The BMT pyrochlores were highly electrical resistive with high dielectric constants, $\varepsilon^{\prime}$ in the range of $\sim 70-85$; dielectric losses, $\tan \delta$ in the order of $10-3$ at frequency $1 \mathrm{MHz}$ and a negative temperature coefficient of permittivities, $\mathrm{TC} \varepsilon^{\prime}$ of $\sim-158$ to $-328 \mathrm{ppm} /{ }^{\circ} \mathrm{C}$.
\end{abstract}

Keyword: C. Dielectric properties; D. Tantalates; Pyrochlores; Ceramics. 